\title{
Sexual Surveillance and Student Sexual Agency: Catholic Moral Teaching and HIV Prevention in a Higher Education Context
}

\author{
Albert Billy Bangirana \\ Sarojini Nadar \\ Sarasvathie Reddy
}

\begin{abstract}
Studies on HIV infection and prevalence at South African University Campuses reveal high levels of HIV infection and prevalence among students. Statistics reveal higher infection rates for female students. It is postulated that these statistics may be attributed to sustained high risk behaviour[s] at university campuses. However, these largely quantitative studies lack a qualitative analysis of the factors associated with high-risk behaviour. Within studies on HIV, there is a significant body of literature that makes linkages to religion, gender and sexuality. What appears to be missing is a focus on Higher education, in particular on how university students might experience HIV prevention models. In discussions on HIV prevention, religion is often seen as providing a moral compass for sexual behaviour. Using surveillance theory and Foucault's theory of power or forces in relation to sexuality, this article critiques the notion of a moral compass by interrogating the foundational teachings of the Catholic Church's HIV prevention model. The article suggests that Albert Bandura's 'self-reactive selfhood reasoning' provides a more adequate moral reasoning framework for students' sexual agency than the Church's framework which is hegemonic and hierarchical.
\end{abstract}

Keywords: Surveillance, Catholic, Sexuality, Morality, HIV, Students, Agency 


\section{Introduction}

Research in HIV and AIDS has been part of the South African Higher Education agenda ${ }^{1}$ for over a decade now (HEAIDS 2010). This initiative was driven by the worrying trajectory in new infections among young people nationally with nearly a third of all infections in the country occurring among 15-24 year olds. (Shisana et al. 2005:37; Right to Care 2016).

Notably, the Higher Education HIV and AIDS programme (HEAIDS) carried out a survey in 2008 and 2009 targeting HIV prevalence and knowledge, attitude, behaviour and practice (KABP) at 21 of the current $26^{2}$ Universities nationally revealing that HIV prevalence among students stood at $3.4 \%$ with KwaZulu-Natal-province having the second highest rate of $6.1 \%$. The prevalence rate among female students was also found to be three-times higher than that of their male counterparts at $4.7 \%$ and $1.5 \%$ respectively (HEAIDS 2010). On the overall, HIV infection and prevalence levels were found to be higher among students aged between 20 to 25 years (HEAIDS 2010:29).

The Human Sciences Research Council (HSRC) also conducted a survey at 21 universities across the country. Despite a slight reduction in HIV infections among 15 to 24 year-olds from $11 \%$ to $8.6 \%$, the recurrence of high risk behavior posed a great challenge to the strides already made (Dell 2010).

${ }^{1}$ The HEAIDS 2008/9 Reports used in this article were part of the Phase 2 project which established the need to channel HIV response through the mission of HEIs i.e. teaching and learning; research and innovation; and community outreach (HEAIDS 2010).

${ }^{2}$ University of South Africa (UNISA), North-West University, University of Pretoria, Tshwane University of Technology, University of Johannesburg, University of KwaZulu-Natal, University of the Free State, Cape Peninsula University of Technology, University of the Witwatersrand, University of Stellenbosch, University of Cape Town, Nelson Mandela Metropolitan University, Walter Sisulu University, Durban University of Technology, University of Limpopo, Vaal University of Technology, University of Zululand, University of the Western Cape, University of Fort Hare, University of Venda, Mangosuthu University of Technology, Rhodes University, Sefako Makgatho Health Sciences University, University of Mpumalanga. Available at: https://businesstech.co.za/news/general/101412/here-are-south-africas-26universities/. (Accessed on 10 January 2018.) 
At the University of KwaZulu-Natal (UKZN), a study targeting HIV sero-prevalence and related factors revealed that HIV prevalence among UKZN students stood at $2.4 \%$ with at least one in every forty students being HIV positive (HEAIDS 2008:8). Female students registered the highest prevalence of $2.8 \%$, when compared to their male counter-parts at $1.8 \%$ (HEAIDS 2008:8) ${ }^{3}$. By and large, risky sexual practices were believed to be contributing to this trajectory (HEAIDS 2008:9). However, a deeper qualitative analysis of the underlying causes to such behavior was largely lacking.

This paper focuses on providing a qualitative inquiry into the factors associated with high-risk behaviour focusing on the students within a Catholic context, though the findings can be applied more broadly. It interrogates the teachings on sexual morality that inform the Catholic Church's ABCD lifestyle model for HIV prevention at the University of KwaZulu-Natal. By employing surveillance theory and Foucault's theory of power/forces, the paper seeks to interrogate how such teachings could be contributing to students' further vulnerability in an HIV context. Drawing on Albert Bandura's 'self-reactive selfhood reasoning', the paper argues for students' sexual agency in moral recourse to sexual risk rather than the Church's approach that is hegemonic and hierarchical. A description of the Catholic Church's ABCD lifestyle model for HIV prevention follows.

\section{The ABCD Lifestyle Model for HIV Prevention}

The ABCD lifestyle model was an initiative of the Southern African Catholic Bishops Conference (SACBC) through their AIDS Desk as a response to HIV and AIDS especially at institutions of higher learning (SACBC 2001). ABCD stands for - Abstinence, Be faithful, Change your lifestyle or else you are in Danger of contracting HIV and AIDS. The model is informed by Catholic teachings on sexual morality and is mainly meant for Catholic students (SACBC 2001). However, students from other denominations are also welcome. This model promotes total abstinence from sex before marriage and a strict moral lifestyle centred on 'gospel values' (SABC 2001). Being a largely

\footnotetext{
${ }^{3}$ The studies used here are critical to this study as they are among the only few published sources of data on students and HIV at Institutions of higher learning in South Africa.
} 
theological model, limited scholarly reflection exists on its contextual relevance (Van der Kivie 2009). Hence, this paper forms part of this emerging field of scholarship. A description of some of the Catholic teachings on sexual morality that are central to this model is provided below.

\section{Selected Teachings on Catholic Sexual Morality}

Since the inception of HIV and AIDS, the Catholic Church has been in the spotlight for its radical stance on sexual morality (Heyward 1994:9-18). Catholic teachings on sexual morality are instituted by the Magisterium ${ }^{4}$ - the teaching authority of the Church and custodian of faith matters, dogma, morals and natural law. Catholic moral teaching must be accepted by all Catholics as an ascent of faith. An example of a teaching on sexuality is: the enforcement of 'chastity in continence' - a directive that prohibits any sexual activity outside marriage, also deemed immoral and gravely sinful (CCC 1994:2350).

Lust is described as a 'disordered desire for or inordinate enjoyment of sexual pleasure' and 'sexual pleasure is morally disordered when sought for itself, isolated from its procreative and unitive purposes' (CCC 1994:2351). Masturbation is considered as 'intrinsically sinful and gravely disordered' (CCC 1994:2351). Sexual intercourse between two unmarried persons (or fornication) is considered a contravention to human dignity and sexuality which is 'naturally ordered to the good of spouses and the generation and education of children' (CCC 1994:2353).

Further, Papal encyclicals like Casti Connubii (1930) and Humane Vitae (1968) outrighlty reject any form of artificial contraception while in Veritatis Splendor (1993) puts a seal on any forms of ideology that could undermine the Church's moral authority in all matters (including sexuality) (Cahill 1996:7).

The Catholic Church justifies its sexual teachings basing on the institution's theological tradition and natural law. The Church through this Moral recourse claims inerrant authority to 'safeguard' its members from the dangers of sexual immorality (Cahill 1996:8). This approach as will be argued could be constraining individual ability to avoid risky sexual behaviour

\footnotetext{
${ }^{4}$ The magisterium is one of the voices of the Catholic Church and is considered as a development of the revelation and tradition. It's the custodian of faith matters, dogma, morals and natural law.
} 
through the control of sexuality. To underscore this argument, we employ two analytical theories, namely, Surveillance theory and Foucault's theory of power/forces.

\section{Theoretical Considerations Surveillance Theory}

Surveillance theory was advanced by Social theorist David Garland in his work 'Panopticon Days: Surveillance and Society' (Garland 2008:3). He describes surveillance as a social control system operating wherever social institutions govern the conduct of individuals' (Garland 2008:3). Theorists such as Kirste Ball, Nichola Green, Hille Koskela and David J. Phillips (2009:352) in a later study defined surveillance as a 'routine, systemic, and purposefully focused process' intended to aggregate individuals into manageable populations, and in part to create 'robust, replicable analytical categories' (Ball et al. 2009: $353)$.

In practice, surveillance methods institutionalise and manage people and their everyday life (Callon 1991:133). They embody intricate centres of power aimed at reinforcing control through socialized hegemonic processes leading to the emergence of vulnerabilities especially in communities or groups under surveillance (Ball et al. 2009:354). Therefore, to underpin surveillance within the sexuality discourse, we now draw on epistemological inferences from Foucault's theory on power or forces in relation to sexuality.

\section{Foucault's Theory on Power or Forces}

In his book, 'History of Sexuality', Michel Foucault expounds on the relationship between surveillance, sexuality and power. He explains that, sexual practices and beliefs are 'socially constructed to benefit a particular configuration of power within a specific historical context' (Foucault 1990[1976]:140). This form of power, he adds, is sanctioned by social institutions (religious or cultural) aiming at the control of sexual subjects (Foucault 1990[1976]:140). Power, in this form, he explains, produces sexual desire and expression or even suppresses it' (Foucault 1990[1976]:140).He thus concludes that the control of sexuality within the morality matrix is but a nexus of 'bio-power' which he describes as a socio-technical process targeting the control of sexual bodies (Foucault 1990[1976]:140). 
It is therefore from this theoretical positioning that we analyse the narratives from some members of the Association of Catholic Tertiary Students (ACTS) to establish whether the Church's approach to sexual morality could be reinforcing hegemonic forms of sexuality that could be detrimental to students' sexual agency in an HIV context.

\section{Students' Views on Catholic Sexual Teachings Methodology}

The students narratives presented in this section were taken from a Doctoral study that interrogates Catholic Teaching on Sexual morality and HIV prevention in a Higher Education Context. This study was ethically cleared by the research office at the University of KwaZulu-Natal. The process of data collection took about six months. Ten individual interviews and two focus group discussions (FDGs) were selected for the purpose of data management (Silverman 2013:44). The sample chosen comprised of male and female students from both the undergraduate and postgraduate levels (Silverman 2013:147). This sample was purposively selected (Melia 1997:26) in consideration of religious affiliation (Catholic), age (18 - 30 years), sex and the period of membership (a year or more) within the Organisation. Participant consent and anonymity (Melia 1997:26) were key considerations in this process and hence pseudonyms are utilised.

\section{Implications of the Impact of Catholic Sexual Teaching on Students}

The selected narratives in this section will be guided by the following key questions: a) How do the students respond to the ABCD lifestyle model of HIV and AIDS prevention at UKZN? b) Why is it implemented this way? The major themes that emerged from the participants' responses have been identified as follows: 'They run away from it', 'Be proud of yourself', 'Sexual desires to satisfy' and lastly 'Accept those who abstain and those who don't'.

\section{'They run away from it'}

This first theme was highlighted from Bongani's response to the following question: Is the ABCD lifestyle model adequate in responding to HIV and AIDS at UKZN? This question was posed during Focus Group A [FGD A]. 
Bongani was 20 years old and in his second year of study.

... It [the Church] is not open because the Church is running away from using the word condomise... because sex is always there they run away from it. I think they must use that word [condom] instead of using Change your lifestyle, use condomise because sex is always there. They are running away at the end of the day... they don't want us, it's like they don't want us to have sex [laughter] but it [sex] is there for us to use condoms. So that's what I think (FGD A $5^{\text {th }}$ May 2014).

Bongani does not only suggest that students are sexual beings but that they do desire to have sex. The assertion 'sex is always there' could imply that there is already an existing choice to be sexually active. However, what is not clear from the inset 'for us to use condoms' is whether they are actually using condoms or he is suggesting that they should be allowed to use them. The subtle nuances like 'it's like they don't want us to have sex' may also mean that the Church's heavy handedness in responding to sexual matters could be suffocating individual responsibility towards sexual choices.

Suzie (19 years) who was part of FGD A interjected,

Society has changed from when the Catholic Church started, it was fine for people not to use contraceptives or condomise because there was no HIV back in the day and then it was fine for people to nurture family planning and all of that. In a way values have changed or deteriorated so now in order to combat this epidemic as it were, we need to face the fact that it is there and people are having sex and are starting at a very young age (FGD A $5^{T H}$ May 2014).

Suzie's words highlight the dynamic nature of our social contexts and the need for progressive engagement in responding to contextual issues. By emphasizing that 'society has changed from when the Catholic Church started', Suzie challenges the rigidity of the Church's moral teaching ${ }^{5}$. Her reference to

5 ... Church teaching on issues like contraception ... is based on 'abstract notions of natural law and [are] outdated, or at the very least scientifically 
changing values and the emphasis on people having sex at a young age cynically subverts hegemonic normativity surrounding the application of Catholic morality in sexual contexts.

\section{'Be proud of yourself'}

This theme emerged from the FGD A discussions on a follow-up question: What are the experiences of the female members of the Association of Catholic Tertiary Students' organisation who get pregnant or have had children out of wedlock? One of the participants, 21 year old Nomfundo who was also a mother gave this response.

... when you have a baby it shows how much stress you have... most people abort that baby but the fact that you carried on with the pregnancy shows how much strong you are so you should be proud of yourself because you managed to go through all that.. I don't know... stigma whatever they gonna say ... you have the baby, and you should be proud of yourself (FGD A $5^{\text {th }}$ May 2014).

A fellow participant, 19 year old Jenny added,

... we are all human, we are and so no one is perfect... for example one gets pregnant and fears to come to church because one will be judged (FGD A $5^{\text {th }}$ May 2014).

The two narratives allude to the underlying stigma some students have to endure in situations where the sanctioned moral code is compromised. The 'fear of being judged' or even rejected, as Nomfundo and Jenny attest, is an indictment to the Church. It unfolds the underlying practical contradictions between theological tradition and pastoral responsibility (Beal, Coriden \& Green 2000:736). The enforcement of the former has led to criticism of the Church for reinforcing stigma (Miller 2001; Machyo 2002; Marcella 2006; Kelly 2006) although some Catholic theologians (see Bate 2003) may differ. It is however evident that stigma is experienced as reflected in Nomfudo's words,

uninformed' and 'are for the most part incomprehensible to the majority of the faithful' (MacElwee 2013). 
'... when you have a baby it shows how much stress you have... most people abort that baby...'. Abortion as a recourse to avoid stigma is in itself immoral and hence a reflection of Nomfundo's dilemma.

Therefore, applying the moral principle of double effect $^{6}$ to Nomfundo's case, reveals the following predicament. The sin of abortion is a 'mortal' sin and thus constitutes grave matter (CCC 1994:1858). Deciding to keep the pregnancy, would be the intended act to protect the life of the unborn child (CCC 1994:1732, 1955). However, this would not mitigate the gravity of the sexual sin since she is unmarried. More so, having an illegitimate child would still be a sin unless both the mother and child are validated by a subsequent marriage covenant or by the rescript of the Holy See. Consequences for not doing this would mean a life of mortal sin and reminder of eternal damnation, and loss of rights to receive sacraments such as the Holy Eucharist (CCL 1139).

As a result of this predicament, Nomfundo could end up defying the Church teaching all together or keeping her sexual life a secret and ignoring the projected guilt. However, as Hardon and Posel (2012) have argued, such an approach could result in the 'concealment of HIV, unscrupulous abortions and rape' (Hardon \& Posel 2012).

\title{
'Sexual desires to satisfy'
}

This theme was taken from the interview with 22 year old Nkosi. The posed question was: What is the position of sexually active but unmarried students with the Association of Catholic Tertiary Students? He responded,

\section{I am a biological being and sometimes you may have sexual desires}

\begin{abstract}
${ }^{6}$ The Principle of 'Double effect' states that: 1 . The intended act must be good in itself. 2. The intended act may not be morally evil. 3. The good effect of the act must be that which is directly intended by the one who carries out the act. 4. The bad effect that results from the act may be foreseen by the agent but must be unintended. 5. The good effect must not be brought about by using morally evil means. 6 . The good effect must be of equal or greater proportion to any evil effect which would result. 7 . Acts that have morally negative effects are permissible only when truly necessary, i.e., when there are no other means by which the good may be obtained (National Council of Bishops 1994: 47).
\end{abstract}


to satisfy. So I don't know when that will be possible for the Church to realise that this is a tricky issue especially for the youth (Individual Interview 14 October 2013).

In his answer Nkosi clearly understands that sexuality is an important component of human existence. In fact he recognizes that as a biological being he will experience sexual feelings. What he finds disturbing is being able to express his sexual feelings without being judged. As Bancroft (2002:15) has rightly observed that sexuality is natural and good. Hence the desire for freedom in being sexual without the fear of reprimand would enhance sexual maturity. Teachings that present sex and sexuality as either evil or only good if expressed in a controlled manner could derail sexual agency (Curran 1993: 1139-1142).

\section{'Accept those who abstain and those who don't'}

This last theme was derived from Focus Group B [FGD B] discussions. The following question was posed to the group: How would you explain abstinence and faithfulness according to the ABCD lifestyle model?

Below is the response from one of the participants, 23 year old Nandipa,

... if you cannot abstain or be faithful then condomise. The church should accept those who abstain and those who don't. As it teaches that we should not judge even in the case of homosexuality, so it should not be judging those who feel they cannot abstain and do use condomise (FGD B 8 May 2014).

Majority of students in this group appeared stunned by the idea that the Church generally expects everyone who is not yet married to abstain. There was also confusion on the faithfulness part as some participants wondered how one can be faithful when they are not allowed to have sex while others argued that this part of the model was meant for those that are already married. However, none in the group was married.

A glance at Nandipa's response suggests that the ideals of abstinence and faithfulness though important are not necessarily sufficient in a context like UKZN. There are gaps between what the Church is advocating for and 
what the students are experiencing sexually. Hence students' experiences call for a constructive approach that facilitates moral maturity - an approach that is gender sensitive and hence supports all students' sexual agency in moral recourse to sexual behaviour, and one that respects individual capacity to selfregulate in situations of potential sexual risk.

\section{Students' Sexual Agency in Moral Recourse to Potential Sexual Risk}

In order to emphasize the need for students' sexual agency in moral recourse to potential sexual risk, we adopt Albert Bandura's 'self-reactive self-hood reasoning'7 as a guiding approach. In his argument on moral responsibility, Bandura points out that a deeper understanding of context is essential (Bandura 2002:102). In this case, context would include students' challenges, needs, sexual realities and worldviews. Hence, this approach is critical to the idea that [students] are incapable of making reasonable moral choices and anything that would undermine moral responsibility (Bandura 2002:102).

In the study on 'Selective Moral Disengagement in the Exercise of Moral Agency', Bandura further notes that 'in the development of a moral self, individuals adopt standards of right and wrong that serve as guides and deterrents for conduct'. He continues to affirm that as part of this regulatory process,

... people monitor their moral standards and perceived circumstances, and regulate their actions by the consequences they apply to themselves. They do things that give them satisfaction and a sense of self-worth. They refrain from behaving in ways that violate their moral standards because such conduct will bring self-condemnation (Bandura 2002:102).

Hence this moral recourse affirms students' innate ability to regulate their sexual conduct in a self-regulatory process. Institutional control of sexuality through a hegemonic moral framework may only derail their ability to self-

7 'Self-reactive selfhood reasoning' involves positive self-sanctioning for good conduct. This means that in situations that may prompt risky behaviour, an individual could opt for self-restraint (Bandura 2002:102). 
regulate. This process - of limited or lack of ability to self-regulate - Hardon and Posel (2012) have established, systematically erodes positive personhood or the feeling of moral goodness thus increasing moral vulnerability. Bandura (2002:106) has referred to this process as 'displaced responsibility'. By this he means that one may view their actions as stemming from the dictates of authority rather than being personally responsible for them (2002:106).

In effect, the process must support the desire for students to take charge of their own 'well-being, to be 'empowered' to think and act in more 'healthy' ways' (Lupton 1997). Supporting this process as an education institution would go far to advance students 'self-reactive ability towards positive moral reasoning' (Bandura 2002: 102). This would go further to entrench as an ongoing exercise of 'evaluative self-influence that regulates and motivates moral conduct' (Bandura 2002:102).

Lastly, Catholic teachings on sexual morality should be interpreted through a critical moral lens rather than an imposed sacrosanct script that is judgmental and stigmatising. The benefits of this approach as Bandura (2002:102) has rightly stated improves the ability to 'self-regulate' and increases personal 'self-worth' thus restraining risky sexual behaviour and HIV.

\section{Conclusion}

The major challenges posed by the HIV and AIDS epidemic at Institutions of Higher Learning in South Africa suggest that the current prevention strategies, especially by religious bodies are not adequate. Through a discussion of the theories of surveillance and Foucault's power or forces, the teachings on sexual morality via the $\mathrm{ABCD}$ model have been shown to contribute more to students vulnerability than preventing it, thus contributing to students' vulnerability to HIV. In this regard both the Church and institutions of higher learning will do well to recognize students' sexual agency in moral recourse rather than impose an approach that is hegemonic and hierarchical.

\section{References}

Aggreton, P. 2000. HIV and AIDS-related Stigmatisation, Discrimination and Denial: Forms, Contexts and Determinants: Research Studies from Uganda and India. Geneva: UNAIDS. 
Alsan, M. 2006. The Church \& AIDS in Africa: Condoms \& the Culture of Life. A Review of Religion, Politics, and Culture 133: 8.

Ball, K., N. Green, H. Koskela \& D.J. Phillips 2009. Surveillance Studies Needs Gender and Sexuality. Surveillance \& Society 6, 4: 352 - 355.

Bancroft, J. 2002. Promoting Sexual Health and Responsible Sexual Behaviour. The Journal of Sex Research 39, 1: 15 - 21.

Bate, C.B. 2003. Catholic Pastoral Care as a Response to the HIV/AIDS

Pandemic in Southern Africa. Journal of Pastoral Care \& Counselling 57, 2: 197-210.

Beal, J.P, J.A. Coriden \& T.J. Green (eds.) 2000. New Commentary on the Code Canon Law. New York: Paulist Press.

Cahill, L.S. 1996. Sex, Gender \& Christian Ethics. Cambridge: CUP.

Coriden, J.A., J.T. Green \& D.E. Heintschel 1985. The Code of Canon Law: A Text and Commentary. New York: Paulist Press.

Curran, C.E. 1993. Sexuality and Sin: A Current Appraisal. In Curran, C.E. \& R.A. McCormick (eds.): Readings in Moral Theology No.8: Dialogue About Catholic Sexual Teaching. New York: Paulist Press.

Enda McDonagh, E. 2000. The Reign of God: Signposts for Catholic Moral Theology. In Keenan, J.F. (ed.): Catholic Ethicists on HIV/AIDS

Prevention. London: Continuum.

Goffman, E. 1963. Stigma: Notes on the Management of Spoiled Identity. New York: Simon \& Schuster Inc.

Foucault, M. [1976] 1990. The History of Sexuality. Volume 1. London: Penguin Books.

Gallagher, R. 2000. Catholic Medical Ethics: Tradition which Progresses. In

Keenan, J.F. (ed.): Catholic Ethicists on HIV/AIDS Prevention. London:

Continuum.

Heyward, C. 1994. Notes on Historical Grounding: Beyond Sexual Essentialism. In James, B.N. \& P.L. Sandra (eds.): Sexuality and the

Sacred: Sources for Theological Reflection. Louisville, Kentucky:

Westminster/ John Knox Press.

Libreria Editrice Vaticana 1994. Catechism of the Catholic Church. London:

Geoffrey Chapman.

Lupton, D. 1997. The Imperative of Health: Public Health and the Regulated Body. London: Sage.

Machyo, C.N. 2000. The Catholic Church and the HIV/AIDS Epidemic in Kenya: An Exploration of Issues. The East Africa Journal of Humanities 
Albert Billy Bangirana, Sarojini Nadar \& Sarasvathie Reddy

\& Sciences 1: 46-60.

MacPhail, C. \& C. Campbell 2000. 'I think condoms are good but, aai, I hate those things': Condom Use among Adolescents and Young People in a Southern African Township. Social Science and Medicine 52, 11: 1613 1627.

Mansell, R. (ed.) 2002. Inside the Communication Revolution: Evolving Patterns of Social and Technical Interaction. Oxford: Oxford University Press.

Melia, M.K. 1997. Producing 'plausible stories': Interviewing Student Nurses. In Miller, G.D. (ed.): Context and Method in Qualitative Research. London: Sage.

Ryan, C. 2003. AIDS and Responsibility: The Catholic Tradition. In Bate, S.C. (ed.): Responsibility in a Time of AIDS: A Pastoral Response by Catholic Theologians and AIDS Activists in Southern Africa. Linden: St. Augustine College of South Africa.

SACBC 2001. A Message of Hope from the Catholic Bishops to the People of God in South Africa, Botswana and Swaziland. Pretoria: Southern African Catholic Bishops Conference.

SACBC 2003. ACTS Policy Documents. Johannesburg: Southern African Catholic Bishops Conference (SACBC).

Silverman, D. 2013. Doing Qualitative Research. $4^{\text {th }}$ Edition. London: Sage Publications.

Warner, M. 1993. Introduction. In Warner, M. (ed.): Fear of a Queer Planet:

Queer Politics and Social Theory. Minneapolis: University of Minnesota Press.

\section{Online Sources}

Bandura, A. 2002. Selective Moral Disengagement in the Exercise of Moral Agency. Journal of Moral Education 31, 2: 101-119. Available at: http:// dx.doiorg/10.1080/0305724022014322. (Accessed on 21 April 2017).

Bussinesstech 2018. Available at: https://businesstech.co.za/news/general/ 101412/here-are-south-africas-26-universities/. (Accessed on 10 January 2018.)

Dell, S. 2015. South Africa: Less HIV in Universities than Nationally. Available at: http://www.universityworldnews.com/article.php?story= 20100409204852226. (Accessed on 18 October 2015.)

Garland, D. 2008. Panopticon Days: Surveillance and Society. Criminal 
Justice Matters 20, 1: 3 - 4. Available at: http://dx.doi.org/10.1080/09627 259508552708. (Accessed on 21 April 2017).

Hardon, A. \& D. Posel 2012. Secrecy as Embodied Practice: Beyond the Confessional Imperative. Culture, Health \& Sexuality. Available at: http://dx.doi.org/10.1080/13691058.2012.726376. (Accessed 20 August 2017.)

HEAIDS 2010. HIV Prevalence and Related Factors - Higher Education Sector Study, South Africa, 2008-2009. Pretoria: Higher Education South Africa. Available at: http://www.ukzn.ac.za/wp-content/miscFiles/publi cations/HEAIDS.pdf. (Accessed on 20 July 2016.)

HEAIDS 2017. History. Available at: http://heaids.org.za/about/history/. (Accessed 1 May 2017).

HEAIDS 2008. HIV and AIDS in the Higher Education Sector: Findings of the Study on HIV Sero-prevalence and Related Factors at the University of KwaZulu-Natal. Pretoria: Higher Education South Africa (HESA). Available at: http://www.ukzn.ac.za/wp-content/miscFiles/docs/reports/ ukzn-hiv-survey-report.pdf. (Accessed on 20 July 2016.)

HSRC 2014. The People Living with HIV: Stigma Index - South Africa 2014. Available at: http://www.fiuc.org/iaup/esap/publications/cuea/eajourn1 aidsch.php. (Accessed on 11 October 2016.).

Kelly, M.J. 2006. HIV and AIDS: A Justice Perspective. Jesuit Centre for Theological Reflection Quarterly Bulletin. Number 69. Lusaka: Jesuit Centre for Theological Reflection. Available at: http://www.develop menteducation.ie/media/documents/hivkelly.pdf. (Accessed on 5 August 2017.)

Machyo, C.N. 2013. The Catholic Church and the HIV/AIDS Pandemic in Kenya: An Exploration of Issues. Available at: Available at: http://www.health-e.org.za/2015/06/09/report-the-people-living--withhiv-stigma-index-south-africa-2014/. (Accessed 17 December 2015.)

McElwee, J.J. 2013. Theologians call Church Sexual Teachings 'incomprehensible,' ask for Lay Input. National Catholic Reporter. November 21. Available at: https://www.ncronline.org/blogs/ncr-today/theologianscall-church-sexual-teachings-incomprehensible-ask-lay-input. (Accessed 18 August 2016.)

Miller, P. 2001. The Lesser Evil: The Catholic Church and the AIDS Epidemic. Conscience 22: 6-13, 41-42. Available at: http://www.catholicsforchoice. org/issues_publications/the-lesser-evil/ (Accessed on 18 August 2017.) 
Reid, G. \& L. Walker 2006. Sex and Secrecy: A Focus on African Sexualities. Culture, Health \& Sexuality: An International Journal for Research, Intervention and Care 7, 3: 185 - 194. Available at: http://dx.doi.org/ 10.1080/13691050412331334353. (Accessed on 21 May 2016.)

Right to Care 2016. S.A. Youth AIDS Mortality has Doubled with Girls at Risk. Available at: http://www.righttocare.org/press-releases/sa-youth-aidsmortality-has-doubled-with-girls-most-at-risk/. (Accessed on 10 January 2018.)

Ryan C. 2007. Taking Ownership of our Sexuality. Available at: http://acts. sacbc.org.za/wp-content/uploads/2012/03/actsnationalconferencereport 2007.pdf. (Accessed 21 August 2017.)

Ryan, C. 2005. Sexuality and Conscience. Johannesburg: St. Augustine College. Available at: http://acts.sacbc.org.za/wp-content/uploads/2012 /03/ Sexuality-and-Conscience-RYAN.pdf. (Accessed on 18 August 2016.)

Shisana, O., T. Rehle, L.C. Simbayi, K. Zuma, S. Jooste, N. Zungu, D. Labadarios \& D. Onoya 2014. South African National HIV Prevalence, Incidence and Behaviour Survey. Cape Town: HSRC Press. Available at: http://www.hsrc.ac.za/en/research-data/view/6871. (Accessed on 31 April 2017).

UNAIDS 2010. UNAIDS Report on the Global AIDS Epidemic 2010. Available at: http://www.unaids.org/globalreport/documents/20101123_ GlobalReport_full_en.pdf. (Accessed on 14/10/2017).

Van der Kevie, L. 2009. Contextual and Cultural Factors that Might Cause Differences between the Patients' Health Experience and the Professional's Health Perception at Four Tapologo HIV/AIDS Clinics around Rustenburg, South Africa. Universiteit Utrecht: Master's Dissertation. Available at: http://aidsoffice.sacbc.org.za/wp-content/ uploads/2012/03/Van-der-Kevie-Contextual-and-Cultural-Factors-reHealth-Expereince-and-Perception-2009.pdf. (Accessed on 20 November 2016).

Albert Billy Bangirana Doctoral Candidate \& Graduate Researcher University of KwaZulu-Natal bangimessage@gmail.com 
Sexual Surveillance and Student Sexual Agency

Sarojini Nadar

Senior Researcher University of Western Cape snadar@uwc.ac.za

Sarasvathie Reddy Higher Education Training Development Unit University of KwaZulu-Natal reddys15@ukzn.ac.za; reddys15@ukzn.ac.za 